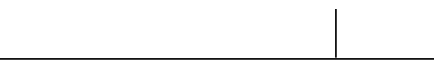

Rev. Latinoam. Psicopat. Fund., VIII, 4, 812-827

\title{
Contribuição ao estudo da dementia paralytica no Brasil*
}

\author{
Juliano Moreira \\ Antonio Panafiel
}

O Brasil, com a sua vasta área que compreende um quinto do continente ocidental, seus vários climas, e a sua população de 21 milhões de habitantes, divididos em muitos grupos étnicos, oferece um campo admirável para o estudo da patologia racial comparada das doenças mentais.

Temos as ditas "raças brancas”, representadas pelos imigrantes portugueses, espanhóis, italianos, alemães, suíços, ingleses, franceses, belgas, húngaros, poloneses, russos, escandinavos, holandeses, dinamarqueses, gregos e sírios, bem como os seus descendentes puros. A China contribui com o "homem amarelo", e a África com o negro. Estes, com o índio aborígine e os numerosos mestiços das várias raças, completam a enumeração, servindo para mostrar o caráter composto da população brasileira.

* Publicado originalmente em inglês: A contribution to the study of dementia paralytica in Brazil. Journal of Mental Science, vol. 53, p. 507-21, 1907. Tradução para o português de Ricardo Corbetta. Revisão técnica e notas de Ana Maria G. R. Oda. Obs.: o artigo original não apresenta lista de referências bibliográficas. 
Se o espaço o permitisse, seria interessante estudar como os vários grupos étnicos têm se misturado para formar aquele que poderia finalmente vir a ser o tipo brasileiro definitivo.

Mesmo sendo um país jovem, o Brasil já oferece muitas oportunidades para o estudo das várias neuropatias. Estatísticas têm indicado o rápido aumento das psicoses, e o governo tem sido obrigado a aumentar os fundos destinados ao cuidado dos alienados.

As causas deste aumento devem ser buscadas no rápido desenvolvimento intelectual da nossa época, no constante crescimento da competição, nos receios das instabilidades política, financeira e comercial e na superpopulação dos nossos grandes centros urbanos, tudo isso tendendo a intensificar a luta pela existência da vida moderna.

Os imensos avanços na vida política e intelectual não foram obtidos sem um grande gasto de energia mental - gasto que deve continuar se quisermos manter o que já atingimos.

Não pretendemos, no presente artigo, revisar as várias formas de alienação mental no Brasil. Queremos apenas apresentar algumas estatísticas sobre a paralisia geral ${ }^{1}$ neste país, adicionando algumas observações sugeridas pelos fatos aqui encontrados, esperando que esta tarefa possa acrescentar algo para o conhecimento desta interessante doença que ocorre em nosso país.

As estatísticas dos nossos hospícios de alienados não mostram qualquer aumento alarmante na ocorrência da doença, mas estas estatísticas são menos confiáveis do que aquelas derivadas das fontes européias, e isso por duas importantes razões: primeiro, o nosso povo, especialmente aqueles das melhores classes sociais, normalmente hospeda um parente afligido em casa, pelo tempo que a sua condição assim o permitir; e, em segundo lugar, a doença, em muitas ocasiões, ainda passa sem ser reconhecida pelo médico generalista, ao menos no seu estado inicial ou quando ela tem uma forma atípica, a síndrome muito freqüentemente sendo diagnosticada como neurastenia, hipocondria ou sífilis cerebral.

As estatísticas do Hospício Nacional de Alienados do Rio de Janeiro mostram, entre 1889 e 1904, a admissão de 9.609 alienados, sendo 5.878 homens e 3.731 mulheres. Do número total de pacientes admitidos, 266 tinham diagnóstico de paralisia geral, uma porcentagem de 2,76. Comparando esta última com as porcentagens dadas pelas estatísticas seguintes, obtidas de outros países, uma marcante diferença pode ser notada.

1. Dementia paralytica, paralisia geral ou ainda paralisia dos alienados são termos usados aqui como sinônimos da mesma entidade clínica, um conjunto de perturbações neurológicas e psíquicas associadas, com evolução progressiva para a demência (N. da R.). 
$\begin{array}{lllllll}R & E & V & I & S & T & A\end{array}$

LATINOAMERICANA

DE PSICOPATO LOGIA

F U N D A M E N T A L

ano VIII, n. 4, dez/2005

Na Rússia, o dr. B. Greidenberg, do Hospital Kharkow Ziemskol, dá 8,8\% para os anos entre 1890 e 1901. Mas o dr. Idanow, a partir das estatísticas de vários hospícios, relata a porcentagem de 18,18.

Em 3.916 casos admitidos para a Clínica Psiquiátrica da Universidade de Moscou, entre 1887 e 1901, o professor S. Soukhanoff e P. Gannouchkine encontraram $17,42 \%$.

Na Alemanha, Weygandt dá a porcentagem como sendo entre dez e 15; Siolli encontrou 26\%.

Em Hamburgo, Kaes encontrou 14\% em 10.148 pacientes alienados.

Na Áustria, Meynert achou 34,6\% em 8.546 casos.

Na Bélgica, em 7.656 casos admitidos em Gheel, Peters relata 16,6\%.

Na Itália, Roscioli encontrou 10,5\%. Em Gênova, Giovanni de Paoli encontrou $31,5 \%$.

O professor Bianchi, nos 555 casos admitidos no Manicômio Provincial de Nápoles, entre 1891 e 1893, relata 13,7\%. O dr. Lojacona relata a porcentagem de 10,75 no Manicômio de Palermo.

Na Dinamarca, as estatísticas do Hospício de Saint Hans, publicadas por Rohwell e Jehersen, mostram em vinte anos uma porcentagem de 17,31. Mas, depois destes, Jacobson deu as estatísticas do mesmo hospício por um período de sete anos, mostrando $23 \%$ de casos de paralisia geral.

Na Inglaterra, o dr. Thurnam relata 24,33\%. O dr. Oscar Woods relata 12,5\% para a Inglaterra, 4\% para a Escócia e apenas 1,1\% para a Irlanda.

Na França, o dr. Planès relata $17 \%$. O dr. Laurent coloca a porcentagem nos hospícios públicos do país em 18. Em Paris ela é bem maior, o Hospício de Charenton mostrando $46 \%$ entre os homens alienados e $5 \%$ nas enfermarias femininas. Nos hospícios privados, a taxa varia entre 35\% e 44,4\%.

Na Suíça, o dr. Camuset, do Hospício de Saint Alban, em Lazère, encontrou em duzentas pessoas admitidas, no período de dez anos, $5 \%$.

Na Grécia, o dr. Yamiris, do Hospício privado Dromocaitis, em Atenas, observou 19,89\% em 1.136 pacientes, entre 1887 e 1902. O dr. Scarpas relata 9,7\% no Hospício Corfu.

Em Portugal, o professor Bombarda, de Rilhafoles, Lisboa, em 2.782 admissões entre 1892 e 1902 encontrou 10,1\%.

Nos Estados Unidos da América, as estatísticas coletadas de várias fontes desde 1849 pelo dr. O. G. Wagner mostram que houve um gradual crescimento de 1,5\% para $12 \%$ sobre o total de admissões. Informações coletadas no Hospital Estadual do Leste de Manhattan [Manhattan State Hospital East] mostram a porcentagem de 8,75.

A raridade da paralisia geral em países tropicais foi afirmada mais de uma vez. Van Brero escreve: “Dementia paralytica ist eine Irrseinsform, welche in 
tropischen Ländern wenig beobachtet wird”. ${ }^{2}$ Em Java, entre 230 pacientes, ele encontrou apenas dois com paralisia geral. Manning, em New South Wales, escreve: "Eu nunca vi ou ouvi algo sobre um paralítico geral”.

Law diz, no Georgetown Reports, em 1887: “No que concerne à paralisia geral dos alienados, pode-se dizer que ela é, indubitavelmente, muito rara na colônia, e era, até há pouco tempo, desconhecida”.

Barnes, em 1891, diz: “A paralisia geral tem sido, repetidas vezes, declarada inexistente; mas ela existe, e não é incomum”.

Friedrichsen, citado por Jeanselme, não viu casos de paralisia geral em Zanzibar - local de clima quente - mas é interessante notar que Ehlers diz que na Islândia - local de clima frio - a síndrome é desconhecida.

Contudo, não acreditamos que o clima influencie a freqüência de ocorrência da doença. A sua incidência é, a nosso ver, regulada pelos fatores da civilização moderna que intensificam o estresse da vida. Esforços mentais e emocionais excessivos, alcoolismo, excessos sexuais etc., enfraquecem a resistência do sistema nervoso, tornando-o menos protegido contra a possibilidade de ser afetado, de forma especial, por toxinas da sífilis e por outros fatores etiológicos, que são causas diretas das mudanças patológicas.

Os percentuais de paralisia geral entre pacientes brasileiros e pacientes estrangeiros, admitidos no Hospital Nacional de Alienados entre 1889 e 1904, foram praticamente os mesmos.

Dos 1.091 pacientes admitidos no hospital privado do dr. Eiras, no Rio de Janeiro, entre 1889 e 1903, 4,3\% sofriam de paralisia geral.

Em 1889, o professor Teixeira Brandão relatou, no Congresso Brasileiro de Medicina do Rio de Janeiro, que dos 670 pacientes observados entre 1883 e 1888 nos hospícios de Niterói e do Rio, apenas 1,6\% eram afetados por paralisia geral. No mesmo Congresso, o dr. Eiras relatou uma porcentagem de 6,22 em 610 admissões no seu hospital; mas aqui é importante notar que, naquela época, quase todos os pacientes da classe mais privilegiada de outros Estados eram levados aos hospitais privados do Rio de Janeiro.

Estado de São Paulo - No hospício público desse Estado, o dr. Franco da Rocha encontrou, em dez anos - 1894 até 1904 - entre 1.057 pacientes brasileiros, uma porcentagem de 3,87 de paralíticos gerais, e entre os 626 estrangeiros, admitidos durante o mesmo período, a porcentagem de 8,3.

Estado do Rio Grande do Sul - No Hospício São Pedro, entre 1884 e 1904, os doutores Dias de Castro e Tristão Torres relataram, nas 2.252

2. Em alemão no original: “A dementia paralytica é uma forma de loucura pouco observada em países tropicais” (tradução de Paulo Dalgalarrondo). 
admissões, 1,46\% de paralíticos, sendo 27 brasileiros, três portugueses, um italiano, um alemão e um africano.

\section{Raça e paralisia geral}

A relação entre raça e alienação mental foi estudada por muitos autores, mas as informações coletadas são muito incompletas e imperfeitas para permitirem generalizações. Nenhuma informação de valor neste ponto pode ser deduzida das estatísticas, devido à definição excessivamente ampla dos grupos étnicos, aceita por médicos norte-americanos e brasileiros. Como ilustração do ponto acima, podemos citar Babcock: “O termo 'negro alienado’ é, aqui, aplicado para todas as pessoas de ascendência africana, sejam negros puros ou mesmo mestiços”. No Brasil, os nossos colegas se satisfazem com a imperfeita classificação: branco, mulato, negro.

Nossas estatísticas mostram que não há imunidade racial para as várias formas de alienação mental.

Há alguns anos, pensava-se que o negro era isento da doença tratada neste artigo. O dr. Roberts, do Hospício de Alienados da Carolina do Norte [Eastern North Carolina Insane Asylum], em 1883, nunca tinha encontrado paralisia geral entre seus pacientes negros. Também o dr. Powell, da Geórgia, em 1886, referiu que jamais vira um caso em um "negro de sangue puro". Mas as investigações de Kiernan, de Berkeley, entre outros, mostram que o negro não goza de tal imunidade.

Nós mesmos observamos a doença em membros de todos os grupos étnicos no Brasil, com a exceção de aborígines puros e dos negros diretamente importados da África. A doença freqüentemente tomava uma forma apática, e não havia uma sintomatologia que fosse peculiar aos vários grupos. Quando tais diferenças existiam, eram individuais, relacionadas ao nível de civilização e de educação atingidos pelo paciente.

A paralisia geral de tipo exaltado foi vista por um dos autores em um mulato, da prole de um europeu e de uma negra. Ele era um inteligente médico do exército, e por seus próprios méritos tinha conseguido uma boa clínica em uma importante capital da União. No curso da sua doença, ele mostrou os delírios de grandeza tão comumente observados nos casos da Europa.

Outro caso interessante foi o de um mulato, capitão de um corpo de engenheiros que se tornou governador de um importante Estado do Brasil. Aqui, também, a doença mostrou toda a exuberante sintomatologia do tipo clássico. 
Em razão da deficiente classificação dos grupos étnicos por meio da cor da pele, nós temos nas estatísticas do nosso Hospital, entre 148 homens brasileiros, 99 brancos, 36 mestiços, dez negros e três não classificados; entre nove brasileiras, três brancas, quatro mestiças e duas negras!

A tabela III mostra as nacionalidades dos pacientes estrangeiros nas estatísticas do Hospital.

\section{Influência do sexo}

Nos diversos países europeus a proporção de mulheres e homens paralíticos gerais varia consideravelmente. Saunder, em 1870, relata a maior proporção, de cinco para sete! Krafft-Ebing, Schüle e Sioli dão um para sete; Greidenberg, um para seis; Stark, um para cinco; Mickle, Siemerling, Keilner, Roscioli, um para quatro; Peters, Kaes, Thurmam, Giovanni de Paoli e Bianchi, um para três; Jacobson, um para 3,6; Weygandt, um para 3,5; Meynert e Idanow um para 3,4 ; Planès um para 2,4.

No Hospital Nacional de Alienados no Rio de Janeiro há uma proporção de uma mulher para 18 homens, num total de 266 paralíticos gerais. Das mulheres, nove são brasileiras e cinco estrangeiras. No Hospital do dr. Eiras, a proporção é de três mulheres para 82 homens. O dr. da Rocha, no Hospital de Alienados de São Paulo, encontrou três mulheres paralíticas para noventa homens, dentre o total de 1.753 alienados observados de 1894 a 1904.

Nossas estatísticas mostram que paralisia geral em mulheres é muito menos comum aqui do que em outros países, sendo a diferença devida talvez ao fato de que nossas mulheres ainda não tenham entrado em competição com o sexo masculino, nos negócios e na vida pública.

A história clínica das mulheres paralíticas gerais no Brasil apresenta as características já conhecidas. Comparada com a do sexo masculino, mostra um curso mais vagaroso, mais uniforme e menos explosivo. As crises maníacas não são tão expansivas, os delírios de grandeza não são tão pronunciados, as exacerbações periódicas e as remissões não são tão freqüentes nem tão bem demarcadas como nos homens. O tipo prevalente é uma forma de demência tranqüila.

\section{Idade}

A grande maioria dos casos ocorre entre 35 e 45 anos de idade. 
$\begin{array}{lllllll}R & E & V & I & S & T & A\end{array}$

LATINOAMERICANA

DE PSICOPATO LOGIA

F U N D A M E N T A L

ano VIII, n. 4, dez/2005

Alienados:

O quadro a seguir é retirado das estatísticas do Hospício Nacional de

\begin{tabular}{|lr|}
\hline De 20 a 23 anos & 3 casos \\
De 24 a 27 anos & 6 casos \\
De 28 a 30 anos & 24 casos \\
De 31 a 35 anos & 58 casos \\
De 36 a 40 anos & 61 casos \\
De 41 a 45 anos & 51 casos \\
De 46 a 50 anos & 28 casos \\
De 51 a 55 anos & 13 casos \\
De 56 a 60 anos & 7 casos \\
De 61 a 65 anos & 4 casos \\
De 66 a 70 anos & 2 casos \\
Idade desconhecida & 9 casos \\
\hline
\end{tabular}

Nas estatísticas do hospital privado do dr. Carlos Eiras, temos:

$\begin{array}{lr}\text { De } 20 \text { a } 30 \text { anos } & 6 \text { casos } \\ \text { De } 31 \text { a } 40 \text { anos } & 18 \text { casos } \\ \text { De } 41 \text { a } 50 \text { anos } & 15 \text { casos } \\ \text { De } 51 \text { a } 60 \text { anos } & 8 \text { casos }\end{array}$

Casos precoces da forma adulta de paralisia geral também ocorrem no Brasil. Encontramos casos em que a doença surgiu aos 23 e aos 24 anos de idade.

Franco da Rocha, de São Paulo, também observou casos de paralisia geral em muitos pacientes de 25 anos de idade.

O sujeito mais jovem com paralisia geral, admitido no Hospício Nacional do Rio de Janeiro, tinha vinte anos de idade.

\section{Paralisia Geral Juvenil}

Antes de 1877, acreditava-se que a paralisia geral dos alienados era uma doença só da idade adulta. Naquele ano, o dr. Clouston descreveu, no Journal of Mental Science, o caso de um rapaz de 16 anos, e apontou que, clínica e patologicamente, a doença que afetava o seu paciente, essencialmente, não diferia da forma adulta. Ele designou-a como “paralisia geral do desenvolvimento”, e considerou ser esse um distúrbio muito raro. Desde seu artigo foram publicados casos na Alemanha, Áustria, França etc., e como o conhecimento desta condição mórbida tornou-se mais comum, tem crescido o número de casos. Krafft-Ebing, 
Karplus, Alzheimer, Gudden, Regis, Haushalter, Mott e outros deram atenção especial às formas precoces de demência paralítica.

Alzheimer, em 1895, numa monografia muito valiosa, foi capaz de coletar apenas 37 casos publicados, aos quais adicionou três de seus casos, com cuidadosos exames microscópicos dos tecidos nervosos. Em 1898, o dr. Thiry coletou e analisou 69 casos publicados, que incluem todos os casos de Alzheimer e mais três casos da clínica de Haushalter, que ele observara. Dr. Frederick Walter Mott, o distinto diretor do laboratório de patologia dos Hospícios da Comarca de Londres [London County Asylums], recentemente publicou as notas sobre 22 casos de paralisia geral juvenil ocorridos nesse local, durante três anos. O número de casos registrados aumenta a cada ano, e apesar do distúrbio ser raro deve-se notar, a partir das observações precedentes, que a doença ocorre com muito mais freqüência do que era suposto anteriormente. Aqui no Brasil só temos conhecimento de dois casos - um do professor Teixeira Brandão, e o outro de um dos autores. Não há dúvida de que um grande número de casos deve restar desconhecido, especialmente no estágio precoce da doença, devido às dificuldades diagnósticas, que são mais ou menos consideráveis.

O seguinte caso foi diagnosticado como "um caso de imbecilidade” por dois médicos não-alienistas:

M., branca, solteira, costureira, 18 anos.

História - Sem insanidade na família (?). Pouco da história pôde ser obtida. Sua mãe era nervosa e excitável. Pai nervoso e sifilítico.

História Pessoal - A paciente nasceu de gestação a termo, e seu nascimento foi sem complicações e natural. Sua saúde era boa até os oito anos de idade. Seus olhos sempre foram saudáveis, mas os dentes de leite eram muito ruins. Ela sempre foi mentalmente deficiente. Foi mandada para a escola aos seis anos de idade, mas tirada de lá porque se considerou que não havia perspectiva de conseguir educá-la.

Aos 12 anos, teve o seu primeiro episódio, enquanto brincava no jardim. Ela, repentinamente, tornou-se inconsciente e ficou por duas horas com o rosto pálido, os lábios azuis e os olhos abertos. Desse momento em diante, foi piorando gradualmente, dia após dia mais fraca mentalmente. De tempos em tempos, ocorria um episódio do mesmo caráter do primeiro. Ela tornou-se muito rancorosa, mordendo os que entravam em contato com ela.

Condição quando vista, ${ }^{3}$ em setembro de 1902 - A paciente tem uma expressão imbecil e infantil, fala de uma maneira infantil e num tom muito nasal.

3. Os autores apontam na descrição do caso de M. as anormalidades típicas da infecção sifilítica do sistema nervoso central: alterações da marcha e dos reflexos tendinosos, disartria resultando em fala pouco clara, rigidez pupilar reflexa (sinal de Argyll-Robertson) etc. (N. da R.). 


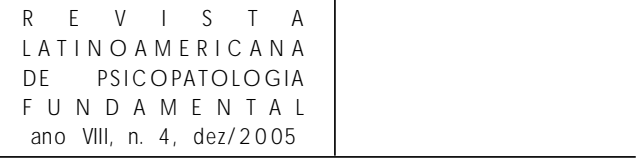

A sua fala é hesitante, trêmula e silábica. Atenção difícil de obter. Parece entender questões muito simples, mas é incapaz de construir uma resposta. Ela pode ficar em pé e caminhar, mas o seu modo de andar é bastante instável, e ela caminha com a base alargada, a custo levantando suas pernas.

Os seus incisivos centrais são em forma de cavilha e com chanfraduras, ${ }^{4}$ tendo ainda erosões lineares do esmalte.

A língua está protraída por uma sucessão de reflexos descoordenados e irregulares, e há marcados tremores fibrilares, tanto na língua como nos músculos da face.

As pupilas estão dilatadas, desiguais, irregulares e não reagem à luz, porém lentamente convergem.

Reflexo patelar ausente. Reflexo plantar presente. Apresenta tremores na extensão dos dedos. O olfato e o paladar são bons e também não há aparentemente perda de tato ou dor. Apesar dos 18 anos de idade, existem poucos pêlos pubianos. Suas mãos e pés são algo azulados e muito frios. Seu apetite é exagerado. Ela perdeu o controle da bexiga e dos intestinos.

\section{Profissões e ocupações}

É fácil ver como certas profissões, mais do que outras, favorecem a ocorrência de várias formas de alienação mental; porém, com relação à paralisia geral, a influência da ocupação não é evidente. Tem sido dito que esta é uma doença de classes mais educadas, poupando os trabalhadores ou assalariados, mas isto não é estritamente verdade, porque, aqui no Brasil, a condição afeta todas as classes, sem consideração quanto à posição financeira, social ou à educação; este fato está se tornando mais evidente, visto que a doença está se tornando mais freqüente. As estatísticas do Hospício Nacional e do Hospital do dr. Eiras mostram que, no Rio de Janeiro, todas as classes e profissões estão representadas entre os paralíticos. No Brasil, se alguma ocupação é especialmente mais propensa a esta doença, parece ser a dos comerciantes (vide Tabela IV).

4. No original, the central incisors are peg-shaped and notched. Os dentes incisivos superiores com a borda inferior em forma de meia-lua (cavilha ou pino) constituem um sinal típico da sífilis congênita, transmitida de mãe para filho durante a gestação. Tal sinal, mais lesão dos olhos (ceratite parenquimatosa) e quadro de surdez súbita na infância formam a chamada tríade de Hutchinson, indicadora clínica de infecção sifilítica adquirida intra-útero (Bleuler, E. Psiquiatria. 15. ed. Rio de Janeiro: Guanabara-Koogan, 1985, p. 174) (N. da R.). 
Dos 266 paralíticos gerais no Hospício Nacional, existem oitenta (excluindo uma mulher) cujas ocupações são desconhecidas, presumindo-se que eles são de baixa classe.

Deve ser observado que mais ou menos a metade dos nossos pacientes é analfabeta. As mulheres eram todas de classe inferior e sem educação formal.

Entre os paralíticos do Hospital São Pedro, Rio Grande do Sul, as ocupações são as seguintes:

\begin{tabular}{|ll|lc|}
\hline ocupações rurais & 9 & pedreiro & 1 \\
comerciantes & 3 & marceneiro & 1 \\
soldados & 2 & alfaiate & 1 \\
funcionário público & 1 & sapateiro & 1 \\
clérigo & 1 & desconhecida & 12 \\
\hline
\end{tabular}

As seguintes informações vêm da prática privada do dr. Moreira:

\begin{tabular}{|ll|ll|}
\hline comerciantes & 8 & médicos & 2 \\
engenheiros & 3 & médico militar & 1 \\
engenheiro militar & 1 & advogados & 2 \\
políticos & 3 & oficial do exército & 1 \\
oficiais da marinha & 2 & capitalista & 1 \\
marinheiro & 1 & & \\
\hline
\end{tabular}

\section{Estado civil}

Dos 266 paralíticos gerais do Hospital Nacional do Rio de Janeiro, 113 são casados, 102 solteiros, 22 viúvos e 29 de estado civil desconhecido.

No hospital do dr. Eiras existem 32 casados, 14 solteiros e 1 viúvo.

Kraepelin, Defendorf e outros autores dizem que a doença é mais freqüente entre os solteiros, mas nossas estatísticas não sustentam a afirmação. Um dos autores deste artigo (dr. Moreira) encontrou, na sua prática privada, apenas dois casos de solteiros.

\section{Duração da Doença}

O quadro a seguir mostra o tempo de permanência dos pacientes no Hospital Nacional, da admissão até a morte. 


\section{1 a 10 dias}

10 a 29 dias

1 mês

2 meses

3 meses

4 meses

5 meses

6 meses

24

7 meses

8 meses

9 meses

10 meses

11 meses

1 ano até 1 ano e meio

1 ano e meio até 2 anos

2 anos até 3 anos

3 anos até 4 anos

TOTAL

231

Dos demais 35 pacientes, 13 ainda estão no hospital; os restantes 22 apresentaram remissões que permitiram o retorno às suas famílias. Relativamente, o aparecimento da paralisia foi mais tardio nas mulheres do que nos homens.

O fato de 190 casos terem falecido no primeiro ano da sua admissão mostra o rápido curso da típica paralisia geral que ocorre no Brasil. Ainda assim, muitos pacientes foram admitidos num estágio bastante avançado. A questão que se levanta é há quanto tempo os pacientes estavam afetados antes da sua admissão. A demência paralítica, na nossa experiência, aqui no Brasil, geralmente leva à morte no curso de poucos anos.

Vez ou outra, ela pode durar seis ou oito anos, algumas vezes até mais tempo, mas o fim geralmente chega em quatro ou cinco anos e, freqüentemente, muito mais cedo.

Entre os casos ocorridos na prática privada de um dos autores (dr. Moreira), só um paciente viveu mais do que cinco anos. Por outro lado, vimos oito paralíticos morrerem poucas semanas depois da ocorrência do segundo estágio, seja por exaustão devido à agitação intensa ou por um simples declínio progressivo no metabolismo vital, o fim sendo precedido por uma série de convulsões apopletiformes. ${ }^{5}$

5. Ou similares às que podem ocorrer na apoplexia, denominação corrente de acidente vascular cerebral, no século XIX e início do XX (N. da R.). 
Em relação ao estado mental dos paralíticos gerais no Brasil, classificamos duzentos casos retirados do hospital e da prática privada, como se segue:

Aqueles com delírios de grandeza ou euforia excessiva, em qualquer estágio da síndrome, foram 96 casos, ou 48\%. Os que exibiam simplesmente uma demência progressiva, foram 72 , ou $36 \%$. Os que eram depressivos e nunca tiveram qualquer excesso de euforia, somavam 32, ou 16\%. Vários casos não tinham delírio de grandeza na admissão, alguns eram até depressivos, e mais tarde desenvolveram tal delírio. Todos estes últimos foram incluídos na primeira categoria. Tendências suicidas não eram raras.

Os sinais físicos desses duzentos casos foram investigados em relação a anormalidades óculo-motoras, pronúncia arrastada ou ininteligível e estado do reflexo patelar, sendo os resultados:

\begin{tabular}{|lr|}
\hline Pupilas desiguais & 95 \\
Pupilas iguais & 98 \\
Pupilas sem registro & 7 \\
Pupilas fixas à luz (uma ou ambas) & 63 \\
Pupilas lentificadas à luz & 98 \\
Pupilas normais à luz & 35 \\
Sem registro & 4 \\
Pronúncia arrastada & 175 \\
Pronúncia clara & 23 \\
Sem registro & 2 \\
Reflexo patelar normal & 12 \\
Reflexo patelar ausente & 55 \\
Reflexo patelar aumentado & 90 \\
Reflexo patelar diminuído & 39 \\
Sem registro & 4 \\
\hline
\end{tabular}

Com relação à etiologia, um dos autores, embora não concordando com o dictum "sem sífilis, sem paralisia geral”, acredita na influência preponderante da sífilis como fator etiológico da síndrome. Em sessenta casos observados por ele, 30\% tinham tido sífilis; em 50\% a sífilis era provável; nos restantes $20 \%$ não havia sinais da doença.

Outros fatores observados nos antecedentes dos pacientes são excessos alcoólicos e sexuais, batidas na cabeça, choque mental e insolação.

Esforço mental demasiado, trabalho excessivo sob circunstâncias difíceis e emoções dolorosas são observados entre as causas da síndrome, que vem, na maioria das vezes, de fatores acumulados no decorrer de vários anos. 
$\begin{array}{lllllll}R & E & V & I & S & T & A\end{array}$

LATINOAMERICANA

DE PSICO PATO LO GIA

F U N D A M N T A L

ano VIl, n. 4, dez/ 2005

TAbela I

Mostra o número de admissões de cada sexo no Hospício Nacional de Alienados do Rio de Janeiro (1889-1904)

\begin{tabular}{|c|c|c|c|c|c|}
\hline \multirow[t]{2}{*}{ Ano } & \multicolumn{2}{|c|}{ Brasileiros } & \multicolumn{2}{|c|}{ Estrangeiros } & \multirow[t]{2}{*}{ Total } \\
\hline & Masculino & Feminino & Masculino & Feminino & \\
\hline 1889 & 33 & 34 & 12 & 14 & 93 \\
\hline 1890 & 181 & 139 & 123 & 55 & 498 \\
\hline 1891 & 110 & 48 & 118 & 26 & 302 \\
\hline 1892 & 162 & 149 & 219 & 80 & 610 \\
\hline 1893 & 185 & 141 & 126 & 58 & 510 \\
\hline 1894 & 267 & 215 & 160 & 64 & 706 \\
\hline 1895 & 276 & 197 & 175 & 58 & 706 \\
\hline 1896 & 232 & 148 & 208 & 77 & 665 \\
\hline 1897 & 241 & 239 & 201 & 61 & 742 \\
\hline 1898 & 278 & 267 & 171 & 69 & 785 \\
\hline 1899 & 241 & 217 & 173 & 83 & 714 \\
\hline 1900 & 229 & 216 & 122 & 48 & 615 \\
\hline 1901 & 253 & 195 & 144 & 49 & 641 \\
\hline 1902 & 247 & 199 & 143 & 54 & 643 \\
\hline 1903 & 275 & 249 & 156 & 37 & 717 \\
\hline 1904 & 265 & 194 & 152 & 51 & 662 \\
\hline Total & 3.475 & 2.847 & 2.403 & 884 & 9.609 \\
\hline
\end{tabular}


TABeLA II

Mostra a nacionalidade dos estrangeiros admitidos no Hospício Nacional de Alienados do Rio de Janeiro (1889-1904)

\begin{tabular}{|c|c|c|c|c|c|c|c|c|}
\hline \multirow[t]{2}{*}{ Nacionalidade } & \multicolumn{2}{|c|}{1889 a 1892} & \multicolumn{2}{|c|}{1893 a 1896} & \multicolumn{2}{|c|}{1897 a 1900} & \multicolumn{2}{|c|}{1901 a 1904} \\
\hline & Masc. & Fem. & Masc. & Fem. & Masc. & Fem. & Masc. & Fem. \\
\hline Portuguesa & 118 & 34 & 309 & 80 & 358 & 106 & 339 & 95 \\
\hline Italiana & 35 & 6 & 86 & 17 & 90 & 35 & 96 & 30 \\
\hline Espanhola & 27 & 8 & 73 & 23 & 90 & 41 & 100 & 35 \\
\hline Francesa & 11 & 6 & 24 & 10 & 91 & 6 & 6 & 8 \\
\hline Alemã & 5 & 3 & 6 & 4 & 17 & 18 & 12 & 5 \\
\hline Austríaca & 3 & 1 & 6 & 2 & 3 & 4 & 6 & 3 \\
\hline Inglesa & 4 & - & 10 & 1 & 10 & - & 7 & 1 \\
\hline Russa & 1 & - & - & 2 & 5 & 2 & 4 & - \\
\hline Polonesa & 3 & - & - & - & 2 & 3 & 1 & 3 \\
\hline Africana & 4 & 15 & 3 & 18 & 10 & 7 & 6 & 3 \\
\hline Turca e Síria & - & - & - & 1 & 1 & 2 & 1 & - \\
\hline Holandesa & - & - & - & - & 1 & - & - & - \\
\hline Dinamarquesa & - & - & 2 & - & 2 & 1 & - & - \\
\hline Belga & - & - & 3 & 3 & 6 & 1 & 1 & - \\
\hline Suíça & - & - & - & - & 2 & 1 & - & 1 \\
\hline Sueca & 1 & - & 5 & - & 7 & 3 & 1 & - \\
\hline Grega & 1 & - & - & - & - & - & 2 & - \\
\hline Romena & - & - & - & - & 1 & - & - & - \\
\hline Chinesa & 2 & - & 1 & - & 2 & - & - & - \\
\hline Norte-americana & 2 & - & - & - & 6 & - & 2 & - \\
\hline Argentina & 1 & - & - & 2 & 2 & 2 & 3 & 2 \\
\hline Uruguaia & 1 & - & - & 1 & - & - & - & - \\
\hline Paraguaia & - & - & - & - & 2 & 1 & - & - \\
\hline Chilena, Peruana, & & & & & & & & \\
\hline Equatoriana & - & - & 1 & - & 1 & - & 2 & - \\
\hline Cubana & - & - & 1 & - & - & - & 1 & - \\
\hline Desconhecida & 253 & 102 & 139 & 93 & 38 & 28 & 3 & 5 \\
\hline TOTAL & 472 & 175 & 669 & 257 & 667 & 261 & 595 & 191 \\
\hline
\end{tabular}


HISTÓ RIA DA

PSIQ UIATRIA

ano VIII, n. 4, dez/ 2005

TABELA IV

Profissões e ocupações dos paralíticos gerais no Hospício Nacional de Alienados do Rio de Janeiro e no Hospital do dr. Eiras, Rio de Janeiro

\begin{tabular}{|c|c|c|}
\hline Profissões e ocupações & $\begin{array}{l}\text { Hospício Nacional de } \\
\text { Alienados (1889-1904) }\end{array}$ & $\begin{array}{l}\text { Hospital dr. Eiras } \\
(1889-1903)\end{array}$ \\
\hline Médico & 2 & 6 \\
\hline Boticário & 2 & - \\
\hline Dentista & - & 2 \\
\hline Advogado & 4 & 3 \\
\hline Tabelião & - & 1 \\
\hline Engenheiro & 1 & 7 \\
\hline Fiscal & 1 & - \\
\hline Arquiteto & 1 & - \\
\hline Desenhista & 1 & - \\
\hline Fotógrafo & 1 & - \\
\hline Mecânico & 1 & - \\
\hline Maquinista & 3 & - \\
\hline Pintor, etc. & 7 & 2 \\
\hline Impressor & 2 & - \\
\hline Operário & 9 & - \\
\hline Carpinteiro & 5 & 2 \\
\hline Cozinheiro & - & 2 \\
\hline Cocheiro, carregador, calceteiro, & & \\
\hline $\begin{array}{l}\text { trabalhador de rua } \\
\text { Estivador }\end{array}$ & $\begin{array}{r}51 \\
2\end{array}$ & $\begin{array}{l}1 \\
-\end{array}$ \\
\hline Pescador & 3 & - \\
\hline Barqueiro & 3 & - \\
\hline Pedreiro & 2 & - \\
\hline Barbeiro & 1 & - \\
\hline Alfaiate & 3 & - \\
\hline Soldado & 4 & - \\
\hline Oficial do exército & 8 & 3 \\
\hline Oficial da marinha & - & 2 \\
\hline Marinheiro & 1 & - \\
\hline Policial & 2 & - \\
\hline Funcionário & 6 & 14 \\
\hline Caixeiro & 9 & - \\
\hline Contador & 3 & 1 \\
\hline Comerciante & 11 & 30 \\
\hline Capitalista & 1 & 3 \\
\hline Mestre-escola & 2 & - \\
\hline Clérigo & 2 & 1 \\
\hline Diplomata & 1 & 1 \\
\hline Músico & 2 & - \\
\hline Palhaço & 2 & - \\
\hline Fazendeiro & 10 & 4 \\
\hline Agricultor & 2 & 1 \\
\hline Criado & 1 & - \\
\hline TOTAL & 172 & 86 \\
\hline
\end{tabular}

